\title{
Surveying drainage culvert use by carnivores: sampling design and cost-benefit analyzes of track-pads vs. video-surveillance methods
}

\author{
Ana Rita A. Mateus • Clara Grilo • \\ Margarida Santos-Reis
}

Received: 7 April 2010 / Accepted: 22 November 2010 / Published online: 23 December 2010

(C) The Author(s) 2010. This article is published with open access at Springerlink.com

\begin{abstract}
Environmental assessment studies often evaluate the effectiveness of drainage culverts as habitat linkages for species, however, the efficiency of the sampling designs and the survey methods are not known. Our main goal was to estimate the most cost-effective monitoring method for sampling carnivore culvert using track-pads and video-surveillance. We estimated the most efficient (lower costs and high detection success) interval between visits (days) when using trackpads and also determined the advantages of using each method. In 2006, we selected two highways in southern Portugal and sampled 15 culverts over two 10-day sampling periods (spring and summer). Using the track-pad method, $90 \%$ of the animal tracks were detected using a 2-day interval
\end{abstract}

A. R. A. Mateus · C. Grilo · M. Santos-Reis

Centro de Biologia Ambiental/Departamento de

Biologia Animal, Faculdade de Ciências C2 $-5^{\circ}$ Piso,

Universidade de Lisboa, 1749-016 Lisboa, Portugal

C. Grilo

Departamento de Biología de la Conservación, Estación Biológica de Doñana (EBD), Consejo Superior de Investigaciones Científicas (CSIC), Calle Américo Vespucio s/n, 41092 Seville, Spain

A. R. A. Mateus $(\varangle)$

Institute of Biology, Leiden University, Sylviusweg 72,

2333BE Leiden, The Netherlands

e-mail: r.mateus@biology.leidenuniv.nl between visits. We recorded a higher number of crossings for most species using video-surveillance $(\mathrm{n}=129)$ when compared with the track-pad technique $(\mathrm{n}=102)$; however, the detection ability using the video-surveillance method varied with type of structure and species. More crossings were detected in circular culverts $(1 \mathrm{~m}$ and $1.5 \mathrm{~m}$ diameter) than in box culverts ( $2 \mathrm{~m}$ to $4 \mathrm{~m}$ width), likely because video cameras had a reduced vision coverage area. On the other hand, carnivore species with small feet such as the common genet Genetta genetta were detected less often using the trackpad surveying method. The cost-benefit analyzes shows that the track-pad technique is the most appropriate technique, but video-surveillance allows year-round surveys as well as the behavior response analyzes of species using crossing structures.

Keywords Survey methods • Incidental wildlife passages • Effectiveness • Road permeability • Road ecology

\section{Introduction}

Mortality and barrier effects are prominent negative impacts of linear transport infrastructures on wildlife (Forman and Alexander 1998). This is especially true for wide-ranging species (e.g., mammalian carnivores), with large territories and 
long dispersal distances, and who regularly come into contact with roads (Gittleman et al. 2001). Increasing landscape permeability and minimizing animal-vehicle collisions (AVCs) are therefore key issues to be considered during road construction and improvement projects (Iuell et al. 2003). The adaptation of incidental crossing structures built for other purposes (e.g., culverts to allow water passage under the roads) is one possible solution to restore animal movements across roads and its role has been widely investigated (e.g., Ascensão and Mira 2006; Clevenger et al. 2001; Mata et al. 2008; Taylor and Goldingay 2003; Yanes et al. 1995).

Survey methods using the track-pad method and camera surveillance have been adopted to evaluate crossing structures use by carnivores and other species, but they differ in the amount and quality of data provided and in the associated costs (Ford et al. 2009). Track detection in varying substrates, such as marble dust or sand, is a common method because of its low cost and effort, and odorless condition (Yanes et al. 1995), besides its ability to distinguish between most species (e.g., Cain et al. 2003; Grilo et al. 2008; Mata et al. 2005; $\mathrm{Ng}$ et al. 2004; Rodriguez et al. 1996). However, it is difficult to differentiate between age classes (adults vs. juveniles) and counts may be underestimated when footprints do not leave species distinguishable tracks (e.g., wolf vs. dog, cat vs. wildcat). Likewise, the use of the trackpad sampling method has limited the ability to assess the effectiveness of culverts as mitigation measures because clear registration of tracks on the tracking material is dependent on external factors such as rain, wind, human disturbance, or livestock. In addition, high animal usage leads to increased overlap of tracks and a more ambiguous interpretation of track counts. Moreover, the interval between visits plays an integral role for an effective evaluation of culvert use, and is dependent on wildlife usage and weather. For example, when the crossing rate is low (e.g. $<$ two tracks/day), daily checking would be redundant and time-consuming.

Consequently, there is a growing interest in other survey methods such as video-surveillance (Dodd et al. 2007a, b; Gordon and Anderson 2003; Hardy et al. 2003; Plumb et al. 2003; Reed et al.
1975). This emerging technique has some advantages over other methods (e.g., motion-sensitive camera and DNA sampling) because it can additionally measure animal response to the presence of the crossing structures by detecting whether an animal hesitates or does not use a crossing structure (Gordon and Anderson 2003; Hardy et al. 2003). The main disadvantages include the high cost of the equipment (Kinley et al. 2003), high power consumption necessitating battery replacement and the susceptibility to vandalism (Stewart et al. 1997).

The advantages and disadvantages in the application of each method are well documented (e.g., Ford et al. 2009) but a comparative cost-benefit analyzes had not been conducted. In this context, we first estimated the most efficient interval between visits (days) using the track-pad method and compared the data collected to the videosurveillance method using the same time interval. We were further interested in detecting the number of small- and intermediate-sized carnivores using the highway drainage culverts.

Materials and methods

Study area

Fifteen drainage culverts were randomly selected along two highways (A2 and A6) crossing Alentejo province in southern Portugal $\left(8^{\circ} 49^{\prime} \mathrm{N}\right.$, $38^{\circ} 46^{\prime}$ E; Fig. 1a): 10 circular culverts (1-1.5 m diameter $)$ and five box culverts $(2 \times 2,3 \times 3$, and $4 \times 4 \mathrm{~m}$ diameter). The region is characterized by a Mediterranean climate (Rivas-Martínez 1981) with hot and dry summers (temperatures often exceeding $40^{\circ} \mathrm{C}$; average annual temperature, $17^{\circ} \mathrm{C}$ ), and with most precipitation (average rainfall, $520 \mathrm{~mm} /$ year) occurring during winter (RivasMartínez 1981) when flood events justify the need for drainage culverts under roads. The landscape is dominated by characteristic Mediterranean agro-forestry areas: cork and holm oak (Quercus suber and Quercus ilex) tree stands combined with open land as pastures, meadows or extensive agriculture, and olive groves. Eight mesocarnivore species (red fox Vulpes vulpes, weasel Mustela nivalis, western polecat Mustela putorius, stone marten Martes foina, Eurasian badger 
Fig. 1 a Drainage culverts location along A2 and A6 highways; b camera unit placed in a culvert
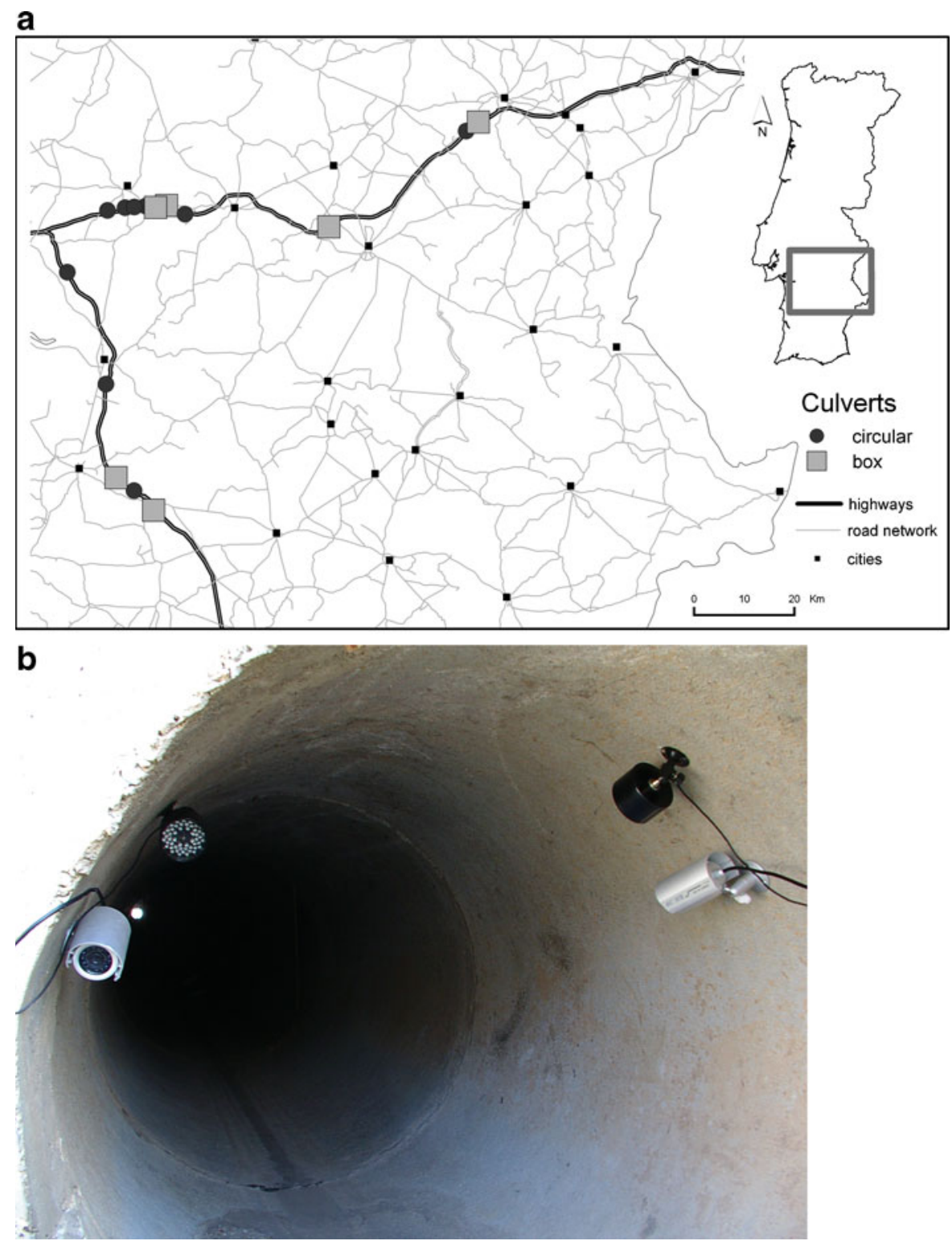

Meles meles, otter Lutra lutra, common genet, and Egyptian mongoose Herpestes ichneumon) are known to occur in the study area (Santos-Reis and Petrucci-Fonseca 1999; Grilo et al. 2009).

\section{Data collection}

Drainage culverts were sampled on two occasions (spring and summer 2006-the driest periods of the year when culverts were least likely to be flooded and marble dust is not washed away), each lasting 10 consecutive days.
Each video-surveillance system (http://www. henrys.co.uk) comprised: (1) two high-resolution black-and-white water-resistant cameras ("BALA" AVC 307R) with 12 automatic-activation infrared LED; (2) two infrared (IR) illuminators (YIL-56DS) with 56 automatic-activation infrared LED, and a lighting capacity of up to $3 \mathrm{~m}$ (IV's); (3) one quad-screen (AVC714) splitter; (4) one videocassette recorder (12 V VCR DVK611) with alarm input; and a (5) $12 \mathrm{~V}$ battery. A Denver portable monitor (DTV-560BW) for image correction, and connection cables with 
additional gear were used during the installation process. In each structure, we placed the cameras and IR illuminators at one entrance and assumed unbiased movement direction across the highway by the animals. We oriented the cameras so they would record animal behavior and presence inside and outside the drainage culvert, which allowed us to also detect failed crossing attempts (Fig. 1b). In order to maximize data collection, the height installation was varied between culverts.

A 180-min VHS videotape set in long-play mode (five times faster than real) allowed $30 \mathrm{~h}$ of recording and we programmed the video recording to occur for a continuous 14-h period at night (6 p.m. to 8 a.m.) because most of the carnivores in our study areas are nocturnal (e.g., SantosReis et al. 2004; Rondinini et al. 2006), with the exception of Egyptian mongoose (Palomares and Delibes 1992) and domestic cats and dogs. Batteries were replaced daily and videotapes every 2 days.

Simultaneously, to record carnivore tracks, a layer of marble dust with $<\sim 1 \mathrm{~cm}$ depth and $\sim 120 \mathrm{~cm}$ length was placed across the width of each culvert (ranging from 1 to $4 \mathrm{~m}$ width). In circular culverts the dust layer was placed at both entrances while in box culverts just halfway.

Because we acquired five video-surveillance systems, we performed three sampling periods (10 days) during each season to survey 15 culverts (five culverts in each sampling). The track-pads were checked daily; and on the fifth day the marble dust was smoothed. Tracks were only recorded when species assignment was possible. For both sampling methods, we recorded species, number of individuals crossing, movement direction, and whether the individuals crossed or hesitate to cross (crossing attempts) the culvert.

\section{Data analyzes}

\section{Interval between visits for track-pads}

To identify the most efficient interval between visits, we measured tracks detectability by recording registered tracks each day over a 5-day period. For example, if five tracks were registered on day 1 , and on day 2 we recorded six tracks (one new track + five tracks from the previous day), this was 0 data loss. Further, if on the third day we only recorded four tracks (i.e., new tracks erased some of the old tracks) then this was a data loss of two and one, regarding the second and first day, respectively. This procedure was performed when both methods were functional. We then compared tracks detectability (total number of crossings/total of structures) for each method for each day. We used Kruskal-Wallis tests followed by post-hoc Dunn tests, to analyze significant differences among the days surveyed and therefore the data loss (Landau and Everit 2004).

\section{Cost-benefit analyzes: video-surveillance vs. track-pads}

We evaluated the cost and benefits of each technique on the basis of detection success and the costs incurred for each survey period (10 days, 15 culverts) along $75 \mathrm{~km}$ of highway. To evaluate detection success for each method, we measured the number of species detected and the average number of successful and failed crossings (detection only in one side of the crossing structure) for each carnivore species: number of crossings/number of structures/number of operative days. We incorporated the most efficient interval of days between visits for track-pads based on the previous analyzes (interval between visits for track-pads) and performed a Wilcoxon Rank Sums test (Landau and Everit 2004) to check the sensitivity of each method to detect presence of tracks for different carnivore species. We also evaluated if differently sized culverts (circular vs. box culverts) were used differently. Human effort was measured in terms of number of visits needed in the field and number of days required to analyze the records. Qualified human resources' costs were estimated using a pay rate of $€ 50$ per day per person. Equipment and travel costs were evaluated for each method using the consumer price index values for 2008 .

Data sets were first tested for normality and homogeneity of variances using KolmogorovSmirnov and Levene's tests, respectively (Sokal and Rohlf 1981). The software STATISTICA v.7.0 for Windows ${ }^{\circledR}$ was used to perform all statistical analyzes and $p<0.05$ was applied as a criterion of significance. 
Table 1 Kruskal-Wallis tests of differences ( $z$ value and significance of the test) among the five sampling days to estimate the best interval between visits to check trackpads without significant loss of information

\begin{tabular}{lll}
\hline Day vs. previous day & $z$ value $^{\mathrm{a}}$ & $p$ level \\
\hline 2nd vs. 1st & 0.18 & $0.98^{*}$ \\
3rd vs. 1st & 2.02 & $0.42^{*}$ \\
4th vs. 1st & 2.92 & $0.03^{* *}$ \\
5th vs. 1st & 4.17 & $0.02^{* *}$ \\
3rd vs. 2nd & 2.05 & $0.40^{*}$ \\
4th vs. 2nd & 3.05 & $0.02^{* *}$ \\
5th vs. 2nd & 4.45 & $0.01^{* *}$ \\
4th vs. 3rd & 1.06 & $0.99 *$ \\
5th vs. 3rd & 2.56 & $0.10^{*}$ \\
5th vs. 4th & 1.49 & $0.99 *$ \\
\hline
\end{tabular}

$* p>0.05$, not significant; $* * p<0.05$, significant

a Post-hoc Dunn test

\section{Results}

Five nocturnal carnivore species were recorded by both methods: red fox, stone marten, Eurasian badger, otter, and common genet. No wildcats, weasels, and polecats were recorded in our sampling even though they occur in the study area (Cabral et al. 2005; Grilo et al. 2009). The crossings rate of diurnal species was minimal and did not affect the analyzes.

Interval between visits for track-pads

Significant data loss was detected in the marble dust when considering each 5-day period (KW: $H=40.54, p<0.01$ ). Post-hoc Dunn tests
(Table 1) documented that significant differences were found between the third and the fifth day, but not between the first and the third day. The 2-day interval was the most effective interval for checking the marble dust for tracks because on the third day there was a $10 \%$ data loss, and on the fourth and the fifth day the data loss increased up to $20 \%$ and $27 \%$, respectively (Fig. 2).

Video-surveillance vs. track-pads cost-benefit analyzes

Video-surveillance was more effective for individual detection $(0.43 \pm 0.12$ successful crossings/ structure/day and $0.08 \pm 0.01$ failed crossings/structure/day) than track-pads $(0.34 \pm 0.10$ successful crossings/structure/day and $0.04 \pm 0.01$ failed crossings/structure/day; W: $T=51, p<$ 0.01; Fig. 3). This result was species-specific and only occurred for the common genet (see Table 2). Although not significantly different $(p>0.05)$, the number of detections differed according to the size of drainage culvert. Video-surveillance was most effective in circular culverts $(0.46 \pm$ 0.05 daily records vs. $0.27 \pm 0.05$ daily records in marble dust), while with box and larger culverts track-pads appeared more effective $(0.29 \pm 0.02$ daily records compared to the $0.25 \pm 0.01$ daily detections for video-surveillance).

A total of 30 field trips were taken (three groups of five crossing structures $\times 10$ days) to change the batteries on the five video-surveillance systems. In comparison, only four trips were
Fig. 2 Success rates for track-pads and videosurveillance methods in detecting carnivore culverts use over five consecutive days

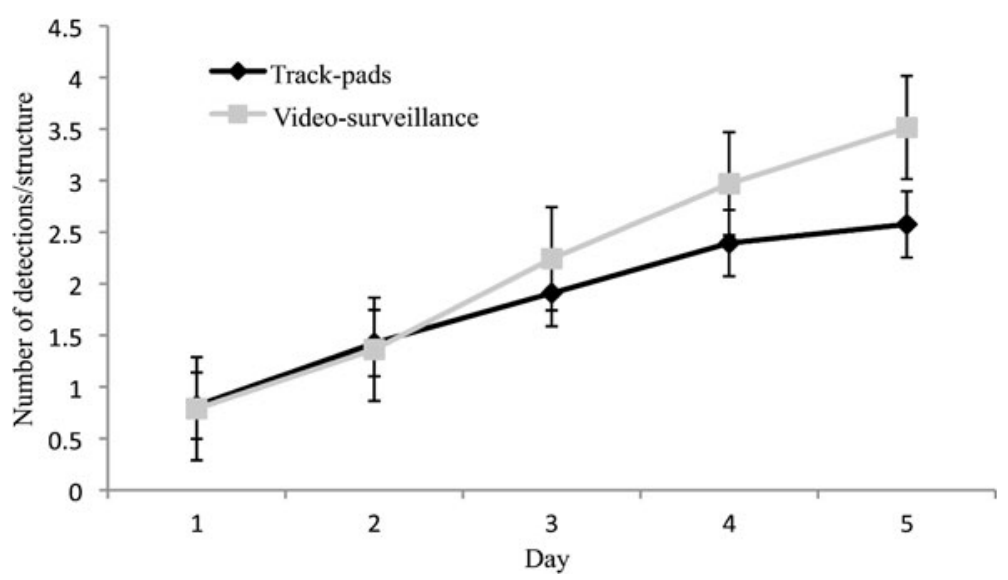


Fig. 3 Mean crossing detections and standard deviation for each species using track-pads and video-surveillance methods. Numbers in the top of columns represent total number of complete crossings and attempts to cross

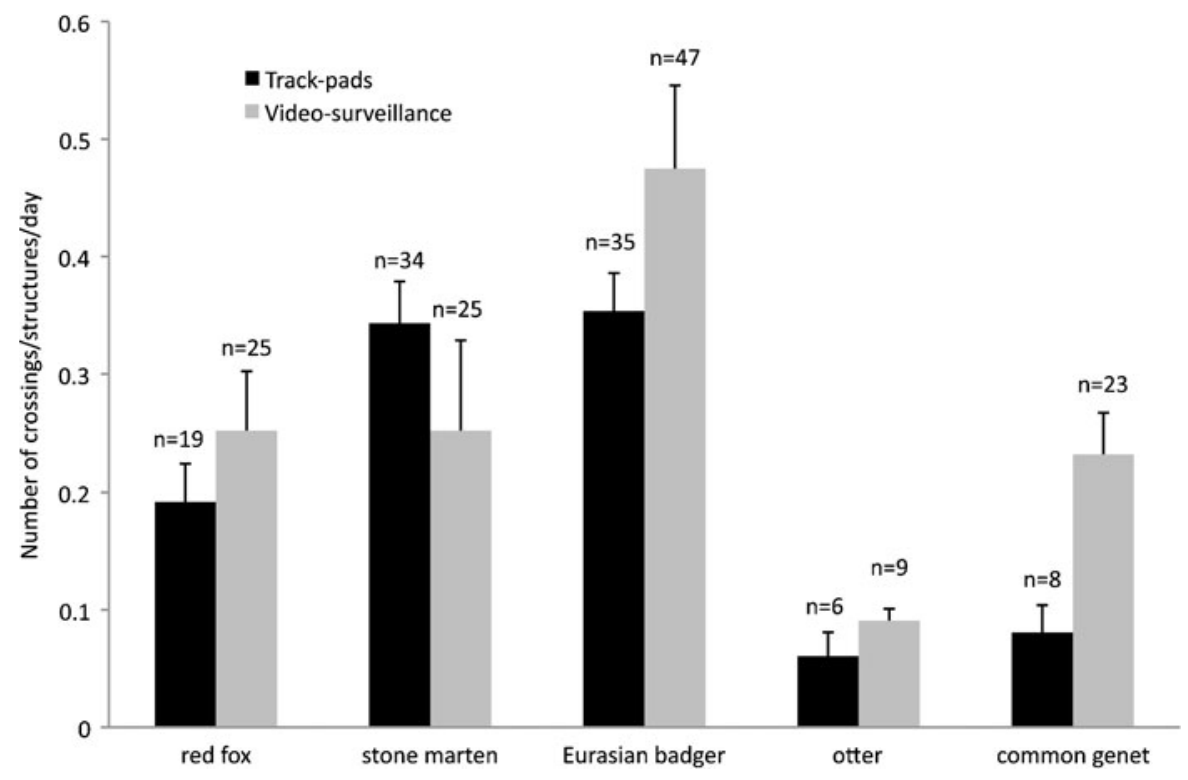

Table 2 Mean crossing rates and respectively standard deviation for both monitoring methods for each species

\begin{tabular}{lllll}
\hline Species & Track-pads & Video-surveillance & $T$ value $^{\mathrm{a}}$ & $p$ level \\
\hline Red fox & $0.19 \pm 0.03$ & $0.25 \pm 0.05$ & 1.5 & $0.13^{*}$ \\
Stone marten & $0.34 \pm 0.04$ & $0.25 \pm 0.08$ & 0.8 & $0.38^{*}$ \\
Eurasian badger & $0.35 \pm 0.03$ & $0.47 \pm 0.07$ & 1.8 & $0.07^{*}$ \\
Otter & $0.06 \pm 0.02$ & $0.09 \pm 0.01$ & 0.8 & $0.97^{*}$ \\
Common genet & $0.08 \pm 0.02$ & $0.23 \pm 0.04$ & 3.5 & $0.01^{* *}$ \\
\hline
\end{tabular}

$* p>0.05$, not significant; $* * p<0.05$, significant

${ }^{a}$ Wilcoxon Rank Sums test

Table 3 Summary of track-pads and video-surveillance costs to survey 15 drainage culverts for 10 consecutive days

\begin{tabular}{|c|c|c|c|c|}
\hline Items & & Cost for each unit ( $C$ 2008) & $\begin{array}{l}\text { Video-surveillance total } \\
\text { costs }(€)\end{array}$ & $\begin{array}{l}\text { Marble dust total } \\
\text { costs }(€)\end{array}$ \\
\hline Personnel & Technician ( 8 h/day) & 50/day & 750 & 200 \\
\hline \multirow[t]{2}{*}{ Travel } & Car rental & 25/day & 250 & 100 \\
\hline & Car fuel & 15/day & 150 & 60 \\
\hline \multirow[t]{5}{*}{ Equipment } & Digital video system & $1,000 /$ each & $5,000^{\mathrm{a}}$ & - \\
\hline & Road safety vest & 5 & 5 & 5 \\
\hline & GPS units & 80 & 80 & 80 \\
\hline & Camera $^{\mathrm{a}}$ & 200 & 400 & - \\
\hline & Wildlife guide & 20 & - & 20 \\
\hline Total & & & 6,635 & 465 \\
\hline
\end{tabular}

${ }^{\mathrm{a}}$ Recommend to add more two infrared cameras when surveying culverts with more than $2 \mathrm{~m}$ width (€50/each) 
needed (marble dust placement plus three visits to check the tracks) to monitor the track-pads. All culverts were checked in 1 day and there was a 2-day interval between checks. In addition to the field work, 5 days to analyze video records were required. We estimated video-surveillance to costs $€ 6,635$, track-pads to cost $€ 465$ over the 10 consecutive days survey (Table 3 ). To complete a long-term survey (e.g., 20 surveys) the costs will increase to $€ 28,485$ for video-surveillance and $€ 7,305$ for the track-pad method. Over the long-term (20 years) it is more cost-effective to integrate video-surveillance than the track-pad method because it is only 3.9 times more expensive, as opposed to 14.3 times more expensive if the study was carried out for only 1 year.

\section{Discussion}

Despite the growing interest in measuring the effectiveness of crossing structures for fauna to increase road permeability (e.g., Yanes et al. 1995; Clevenger et al. 2001; Grilo et al. 2008; Mata et al. 2008), there is an uncertainty when determining the most appropriate method to best evaluate their effectiveness. In fact only one study has compared the passage delectability among the methods, as well the cost-benefit for each method (Ford et al. 2009). This study showed that the data collection method can play a crucial role on the accuracy of the findings and therefore in the evaluation of the use and effectiveness of crossing structures for safe wildlife passage.

Each method, video-surveillance and trackpad, offer both advantages and limitations for monitoring small- and intermediate-sized carnivore movement at drainage culverts along highways. With this study we found that: (1) daily surveys of the marble dust is not needed; a 2day interval being sufficient, and (2) although video-surveillance offers better detection capabilities, track-padding is the most suitable method for dry seasons and large-scale studies. Nevertheless, a long-term survey (including periods when the culverts are flooded and marble dust cannot be used; e.g., 20 surveys of 10 consecu- tive days) performed by video-surveillance is $\sim 14$ times less cost-effective than only one survey (10 consecutive days) when comparing with track-pad method.

With a carnivore's crossing rate similar to this region $(0.68 \pm 0.01$ crossings/culvert/day), 2 days are the recommended period between monitoring visits for track-pad technique. A longer interval between visits can lead to the degradation of data quality. Because the recommended interval is influenced by crossing rate and the species under consideration, the interval between checks may be extended or decreased. Thus, an experimental pre-study period prior to track-pads sampling strategy is recommended.

Both the track-pads and video-surveillance methods detected the number of species crossings. In general, video-surveillance was more effective in detecting the number of successful and incomplete crossing attempts, thus the relative proportion of crossings between species. This result might be explained by three important limitations of the track-pad method: (1) unidentified tracks that can underestimate the real value of crossing rates with this method (in our study $5 \%$ of the tracks were not identified), (2) underestimation of small-footed species, such as the common genet, due to obliteration by larger tracks (66\% of data loss), and (3) misclassification of successful crossing attempts (a track on one side of the structure did have a corresponding track on the other side).

In comparison to the track-pad method, videosurveillance provided additional data such as the timing of the crossing event, group size, and sex and age of the individuals (e.g., Olsson et al. 2008). Time of crossing use is an important indicator of why an animal may be using a culvert and can be used to determine the most appropriate mitigation measures to increase carnivore passage use.

The low performance of the video-surveillance method for box culverts can be explained by the poor ability of IR illuminators to cover the entire target area (Stewart et al. 1997). As a result the capability of video-surveillance to measure animal behavior is limited to the area of observation. The addition of two more IR cameras for box culverts may assist in collecting behavior data; however, 
due to high costs of equipment budget constraints would make this difficult.

Determining the most appropriate surveying method will depend on the goals, surveying time, and budget for the study. High equipment cost and survey effort was considered the main disadvantage of video-surveillance (Kinley et al. 2003). Video-surveillance was $\sim 14$ times more expensive than track-pads but an increased detection reliability $(10 \%)$ during a 2-day interval period may off-set the high costs. Since the video-surveillance needs a major start-up investment, this technique may be justified when there is: (1) a low number of crossing structures, (2) a need for continuous longterm survey, (3) a focus on small-sized species, (4) high density of individuals in an area, and (5) an interest in behavioral traits of individuals while approaching and/or crossing a passage. Otherwise, track-pads using marble dust are an efficient and certainly less expensive method that is best suited to regions with dry conditions, such as in the arid or semi-arid regions of in the southern Mediterranean.

Acknowledgements C. Grilo was supported by a Ph.D. grant (SFRH/BD/10600/2002) from the Fundação para a Ciência e Tecnologia. The authors thank Brisa AutoEstradas de Portugal S.A. for providing financial and logistical support for this project. Special thanks to Rui Raposo, Alexandre Pirra, Rui Casado, Joaquim Nobre, and Gertrudes Ferro for their help in transport and setting up the equipment. We would also like to thank all the volunteers that collaborated with us to complete the field work and view the videotapes. We thank Henrique Cabral, Filomena Magalhães, Mafalda Costa, and Fernando Ascensão for statistical help. We thank Ana Marta Serronha for the picture. We also would like to thank Maria Teresa Rebelo and, in particular, John A. Bissonette and Kari Gunson for the valuable critical comments on the manuscript and for the English review.

Open Access This article is distributed under the terms of the Creative Commons Attribution Noncommercial License which permits any noncommercial use, distribution, and reproduction in any medium, provided the original author(s) and source are credited.

\section{References}

Ascensão, F., \& Mira, A. (2006). Factors affecting culvert use by vertebrates in two roads of southern Portugal. Ecological Research, 22, 57-66.
Cabral, M. J., Almeida, J., Almeida, P. R., Dellinger, T., Ferrand de Almeida, N., Oliveira, M. E., et al. (2005). Livro Vermelho dos Vertebrados de Portugal. Lisboa: Instituto da Conservação da Natureza.

Cain, A. T., Tuovila, V. R., Hewitt, D. G., \& Tewes, M. E. (2003). Effects of a highway and mitigation projects on bobcats in Southern Texas. Biological Conservation, 114, 189-197.

Clevenger, A. P., Chrunszcz, B., \& Gunson, K. (2001). Drainage culverts as habitat linkages and factors affecting passage by mammals. Journal of Applied Ecology, 38, 1340-1349.

Dodd, N. L., Gagnon, J. W., Boe, S., \& Schweinsburg, R. E. (2007a). Assessment of elk highway permeability by using global positioning system telemetry. Journal of Wildlife Management, 71, 1107-1117.

Dodd, N. L., Gagnon, J. W., Manzo, A. L., \& Schweinsburg, R. E. (2007b). Video-surveillance to assess highway underpass use by elk in Arizona. Journal of Wildlife Management, 71, 637-645.

Ford, A. T., Clevenger, A. P., \& Bennett, A. (2009). Comparison of methods of monitoring wildlife crossing-structures on highways. Journal of Wildlife Management, 7(73), 1213-1222.

Forman, R. T., \& Alexander, L. E. (1998). Roads and their major ecological effects. Annual Review of Ecology and Systematics, 29, 207-231.

Gittleman, J. L., Funk, S., Macdonald, D., \& Wayne, R. (2001). Carnivore conservation. Cambridge: The Zoological Society of London.

Gordon, K. M. \& Anderson, S. A. (2003). Mule deer use of underpasses in western and southeastern Wyoming. In: C. L. Irwin, P. Garrett \& K. P. McDermott (Eds.), Proceedings of the international conference on ecology and transportation (pp. 309-318). Raleigh: Center for Transportation and Environment.

Grilo, C., Bissonette, J. A., \& Santos-Reis, M. (2008). Response of carnivores to existing highway culverts and underpasses: Implications for road planning and mitigation. Biodiversity and Conservation, 17, 1685-1699.

Grilo, C., Bissonette, J. A., \& Santos-Reis, M. (2009). Spatial-temporal patterns in Mediterranean carnivore casualties: Consequences for mitigation. Biological Conservation, 142, 301-313.

Hardy, A., Clevenger, A. P., Huijser, M., \& Neale, G. (2003). An overview of methods and approaches for evaluating the effectiveness of wildlife crossing structures: Emphasizing the science in applied science. In: C. L. Irwin, P. Garrett, \& K. P. McDermott (Eds.), Proceedings of the international conference on ecology and transportation (pp. 319-330). Raleigh: Center for Transportation and Environment.

Iuell, B., Bekker, G. J., Cuperus, R., Dufek, J., Fry, G., Hicks, C., et al. (2003). Wildlife and traffic: An European handbook for identifying conflicts and designing solutions. United Kingdom: KNNV Publishers.

Kinley, T. A., Page, H. N., \& Newhouse, N. J. (2003). Use of infrared camera video footage from a wildlife protection system to assess collision-risk behavior by deer in Kootenay National Park, British Columbia. Invermere: Sylvan Consulting Ltd. 
Landau, S., \& Everit, B. S. (2004). A handbook of statistical analyses using SPSS. FL: Chapman \& Hall-CRC.

Mata, C., Hervás, I., Herranz, J., Suaréz, F., \& Malo, J. E. (2005). Complementary use by vertebrates of crossing structures along a fenced Spanish motorway. Biological Conservation, 124(3), 39-405.

Mata, C., Hervás, I., Herranz, J., Suárez, F., \& Malo, J. E. (2008). Are motorway wildlife passages worth building? Vertebrate use of road-crossing structures on a Spanish motorway. Journal of Environmental Management, 88, 407-415.

Ng, S., Dole, J. W., Sauvajot, R., Riley, S., \& Valone, T. (2004). Use of highway undercrossings by wildlife in southern California. Biological Conservation, 115, 499-507.

Olsson, M. P. O., Widen, P., \& Larkin, J. L. (2008). Effectiveness of a highway overpass to promote landscape connectivity and movement of moose and roe deer in Sweden. Landscape and Urban Planning, 85, 133-139.

Palomares, F., \& Delibes, M. (1992). Circadian activity patterns of free-ranging large gray mongooses, Herpestes ichneumon, in southwestern Spain. Journal of Mammalogy, 73, 173-177.

Plumb, R. E., Gordon, K. M., \& Anderson, S. H. (2003). Pronghorn use of wildlife underpass. Wildlife Society Bulletin, 31, 1244-1245.

Reed, D. F., Woodward, T. N., \& Pojar, T. M. (1975). Behavioral response to mule deer to a highway underpass. Journal of Wildlife Management, 39, 361-367.

Rivas-Martínez, S. (1981). Les étages bioclimatiques de la vegetación de la Peninsule Iberique. Anales del Jardín Botánico de Madrid, 37, 251-268.
Rodriguez, A., Crema, G., \& Delibes, M. (1996). Use of non-wildlife pasajes across a high speed railway by terrestrial vertebrates. Journal of Applied Ecology, 33, 1527-1540.

Rondinini, C., Ercoli, V., \& Boitani, L. (2006). Habitat use and preference by polecats (Mustela putorius L.) in a Mediterranean agricultural landscape. Journal of Zoology, 269, 213-219.

Santos-Reis, M., \& Petrucci-Fonseca, F. (1999). Carnívoros. In: ICN/CBA (Eds.), Mamíferos terrestres de Portugal Continental, Madeira e Açores. Lisboa: Instituto de Conservação da Natureza/Centro de Biologia Ambiental.

Santos-Reis, M., Santos, M. J., Lourenço, S., Marques, T., Pereira, I., \& Pinto, B. (2004). Relationships between stone martens, genets and cork oak woodlands in Portugal. In: D. J. Harrison, A. K. Fuller, \& G. Proulx (Eds.), Marten and fishers in human altered landscapes: An international perspective. Massachusetts: Kluwer Academic Publishers.

Sokal, R. R., \& Rohlf, F. J. (1981). Biometry. New York: W. H. Freeman.

Stewart, P., Ellwood, S., \& Macdonald, D. (1997). Remote video-surveillance of wildlife-An introduction from experience with the European badger Meles meles. Mammal Review, 27(4), 185-204

Taylor, B. D., \& Goldingay, R. L. (2003). Cutting the carnage: Wildlife usage of road culverts in north-eastern New South Wales. Wildlife Research, 30, 529-537.

Yanes, M., Velasco, J. M., \& Suaréz, F. (1995). Permeability of roads and railways to vertebrates: The importance of culverts. Biological Conservation, 71, 217-222. 